\title{
Análise da sinergia de resíduos agroindustriais submetidos a biodigestão anaeróbia visando biogás para aproveitamento energético
}

Este estudo teve como objetivo analisar o desempenho de resíduos agroindustriais, oriundos de uma Cooperativa de alimentos do Vale do Taquari (Rio Grande do Sul), submetidos ao processo de biodigestão anaeróbia visando a obtenção de biogás para fins energéticos. 0 experimento foi focado na variação do percentual de dejeto suíno em uma mistura de lodos de estações de tratamento de efluentes, possibilitando a avaliação de sua influência na quantidade e qualidade do biogás gerado, uma vez que este resíduo é produzido em maior volume pela Cooperativa e possui grande aplicabilidade em processos de digestão anaeróbia. Os resultados obtidos indicaram que a sinergia entre os substratos combinados foi positiva. A melhor eficiência de produção de biogás foi obtida na mistura com $60 \%$ de dejeto suíno e $40 \%$ da mistura de lodos e sangue. Constatou-se que, mesmo exigindo tempos de detenção hidráulico diferentes, os maiores volumes de biogás nas misturas foram produzidos nos primeiros dias do processo. Conclui-se que a codigestão de biomassas residuais é capaz de promover melhores rendimentos na produção de biogás para fins de seu aproveitamento como fonte renovável de energia, se comparada ao desempenho da digestão do dejeto suíno, que é uma biomassa tipicamente empregada como substrato para a geração de biogás

Palavras-chave: Biomassa; Energia Renovável; Tratamento Anaeróbio; Dejeto Suíno.

\section{Analysis of the synergy of agro-industrial waste submitted to anaerobic biodigestion aiming biogas for energy development}

\begin{abstract}
The objective of this study was to analyze the performance of agroindustrial residues from a food cooperative in the Taquari Valley (Rio Grande do Sul), submitted to the anaerobic biodigestion process to obtain biogas for energy purposes. The experiment was focused on the variation of the percentage of swine manure in a mixture of sludge from effluent treatment plants, allowing the evaluation of its interference or contribution in the quantity and quality of the biogas generated, since this residue is produced in greater volume and has great applicability in anaerobic digestion processes. The results indicated that the synergy between the combined substrates was positive. The best biogas production efficiency was obtained in the mixture with $60 \%$ swine manure and $40 \%$ of the sludge and blood mixture. It was found that, even requiring different hydraulic holding times, the higher biogas volumes in the blends were produced in the first days of the process. It is concluded that the codigestion of residual biomass is able to promote better yields in the production of biogas for its use as a renewable source of energy, when compared to the performance of the digestion of swine manure, which is a biomass typically used as a substrate for generation of biogas.

Keywords: Biomass; Renewable Energy; Anaerobic Treatment; Swine Manure.
\end{abstract}

Topic: Sistemas de Energia Sustentável

Reviewed anonymously in the process of blind peer.
Received: 09/03/2017

Approved: 09/05/2017
Camila Hasan

Universidade do Vale do Taquari, Brasil http://lattes.cnpq.br/1967237941851023 chasan@universo.univates.br

Munique Marder

Universidade do Vale do Taquari, Brasil http://lattes.cnpq.br/6070031909886243 mmarder@univates.br

\section{Anny Kariny Feitosa}

Universidade do Vale do Taquari, Brasil

http://lattes.cnpq.br/6604861578850716 anny.feitosa@gmail.com
Cezar Augusto Machado

Universidade Federal do Rio Grande do Sul, Brasil http://lattes.cnpq.br/7939094002344851

cezar.machado@univates.br

Tamara Engelmann Gonçalves

Universidade do Vale do Taquari, Brasil

http://lattes.cnpq.br/6933401305406596 tegoncalves@univates.br

\section{Tiago Feldkircher}

Universidade Federal do Rio Grande do Sul, Brasil http://lattes.cnpq.br/2968708128234466 tiagof@univates.br

\section{Odorico Konrad}

Montanuniversität Leoben, Áustria http://lattes.cnpq.br/9946679953072196 okonrad@univates.br

Referencing this:

DOI: 10.6008/SPC2179-6858.2017.003.0018

HASAN, C.; MARDER, M.; FEITOSA, A. K.; MACHADO, C. A.; GONÇALVES, T. E.; FELDKIRCHER, T.; KONRAD, O.. Análise da sinergia de resíduos agroindustriais submetidos a biodigestão anaeróbia visando biogás para aproveitamento energético. Revista IberoAmericana de Ciências Ambientais, v.8, n.3, p.190-199, 2017. DOI: http://doi.org/10.6008/SPC2179-6858.2017.003.0018 


\section{INTRODUÇÃO}

O incremento nas demandas energéticas é desproporcional ao desenvolvimento de fontes renováveis de energia (RÜHL et al., 2012), ao tempo em que minimizar a dependência da sociedade em fontes não-renováveis é indispensável para o desenvolvimento de uma sociedade industrial sustentável e para a gestão eficaz das emissões de gases de efeito estufa (CLARK et al., 2012).

Explorações agrícolas e pecuárias, destilarias, fábricas de lacticínios, matadouros, esgotos domésticos, entre outros, geram um grande volume de resíduos orgânicos, que por sua vez, apresentam uma alta carga poluente (COSTA, 2011). As frações orgânicas de resíduos são consideradas fontes promissoras de energia renovável e seu potencial pode ser explorado através de um processo de digestão anaeróbia. A geração de energia a partir do biogás é uma alternativa ambiental considerável; no entanto, o desenvolvimento desta prática depende de um melhor entendimento do processo de produção de biogás (CANDIANI et al., 2015).

Nos cenários futuros de uma economia baseada em biocombustíveis, a valorização sustentável dos recursos de biomassas, por meio da digestão anaeróbia, será uma opção viável e necessária (EL ACHKAR et al., 2016). Neste processo, microrganismos anaeróbios de espécies pertencentes ao grupo de bactérias hidrolíticas fermentativas, acetogênicas produtoras de hidrogênio e metanogênicas, são as responsáveis pela degradação da matéria orgânica. A cooperação entre diferentes tipos de culturas bacterianas é necessária para que haja a bioconversão da matéria orgânica poluente em metano (SALOMON et al., 2005).

O biogás destaca-se como um potencial combustível para geração de energia e pode ser utilizado com os mesmos padrões do gás natural fóssil, quando purificado (MIYAWAKI, 2014). É considerado uma fonte renovável de energia e pode ser produzido a partir de resíduos orgânicos como o esgoto e resíduos agroindustriais, apresentando-se como uma importante alternativa energética, em condições de desempenhar expressivo papel na substituição do petróleo e de seus derivados (FERRAREZ et al., 2010).

Prati (2010) descreve o biogás como sendo uma mistura de gases, cujo tipo e percentual variam de acordo com as características dos substratos e das condições de funcionamento do processo de biodigestão. Os principais constituintes do biogás são o metano $\left(\mathrm{CH}_{4}\right)$, o dióxido de carbono $\left(\mathrm{CO}_{2}\right)$, o sulfeto de hidrogênio $\left(\mathrm{H}_{2} \mathrm{~S}\right)$, a amônia $\left(\mathrm{NH}_{3}\right)$ e água (umidade), sendo os dois primeiros predominantes (KONRAD et al., 2013). O metano apresenta um elevado poder calorífico, que torna viável a sua queima para a geração combinada de energia térmica e elétrica (cogeração). A liberação deste gás diretamente para a atmosfera é nociva, pois o mesmo tem um potencial de aquecimento global 21 vezes maior que o dióxido de carbono. Quando a digestão anaeróbia é realizada em biodigestores desenvolvidos com o objetivo de recuperação energética, a mistura gasosa gerada é utilizada como combustível (COSTA, 2011).

A Região Sul do Brasil tem se mostrado relevante nas atividades do ramo da produção de alimentos, com ênfase na criação de animais para abate e processamento. O Vale do Taquari é um dos principais produtores de suínos do Estado, concentrando a criação e o abate. A atividade, fundamentada no sistema de integração verticalizada, tem grande importância econômica, mas exige o manejo adequado dos dejetos (DAL SOLER, 2012). Os rendimentos de biogás a partir da digestão anaeróbia destes dejetos podem variar 
principalmente em função da qualidade do resíduo adicionado ao biodigestor e do seu grau de diluição. Outros fatores também podem contribuir para oscilações nestes rendimentos, como a adição de um substrato que complemente a composição do dejeto (HIDALGO et al., 2014).

Neste sentido, o presente estudo teve por objetivo avaliar a sinergia de resíduos agroindustriais (dejeto suíno, sangue e lodos de estação de tratamento de efluentes) submetidos ao processo de biodigestão anaeróbia que, combinados em diferentes proporções, pudessem ofertar a melhor opção de geração de biogás para aproveitamento energético.

\section{METODOLOGIA}

\section{Origem das biomassas avaliadas}

Os substratos orgânicos utilizados para os testes (lodos, sangue e dejeto suíno) caracterizam-se como resíduos das atividades agroindustriais, relacionadas ao ramo alimentício de uma cooperativa do Vale do Taquari. A geração dessas biomassas residuais resultantes do processo produtivo da Cooperativa, representava em 2015, 4.739ton/mês, sendo distribuídas em 2.695ton/mês de dejeto suíno (DS) proveniente de três Unidades Produtoras de Leitões (UPL) e 2.044ton/mês correspondentes a subprodutos dos demais processos produtivos e lodos das estações de tratamento de efluentes de três Unidades Produtivas, conforme descritos quantitativamente e percentualmente na tabela 1. Todas as biomassas citadas na Tabela 1 fizeram parte da mistura avaliada, além da participação do inóculo (lodo anaeróbio digerido) e do dejeto suíno (DS) oriundo de uma UPL.

Tabela 1: Quantificação de biomassas geradas pela Cooperativa.

\begin{tabular}{|l|c|c|}
\hline \multicolumn{1}{|c|}{ Resíduo/Origem } & Quantidade Gerada (ton/mês) & \% \\
\hline Lodo Flotado (Frigorífico de Suínos) & 653 & 31,95 \\
\hline Lodo Ativado desidratado (Frigorífico de Suínos) & 18 & 0,88 \\
\hline Sangue (Frigorífico de Suínos) & 172 & 8,42 \\
\hline Lodo Flotado (Laticínios) & 183 & 8,95 \\
\hline Lodo Ativado (Laticínios) & 183 & 8,95 \\
\hline Lodo Flotado e Ativado (Frigorífico de Aves) & 625 & 30,58 \\
\hline Sangue (Frigorífico de Aves) & 210 & 10,27 \\
\hline Total & $\mathbf{2 . 0 4 4}$ & $\mathbf{1 0 0}$ \\
\hline
\end{tabular}

\section{Preparo das amostras}

Para a mistura destes resíduos, foram considerados inicialmente os percentuais que cada substrato representava, em termos de volume gerado, dentro da cooperativa, com exceção do dejeto suíno. A inclusão do dejeto suíno na mistura teve a sua participação percentual nos experimentos relacionada ao volume de amostragem $(420 \mathrm{~mL})$ variável de 10 a $100 \%$, respeitando-se intervalos de $10 \%$. Foram preparados $10 \mathrm{~L}$ da mistura de lodos e sangue da forma mais homogênea possível para ser utilizada em todas as triplicatas. Deste modo o percentual descrito na tabela foi seguido e a variável nos reatores foi o volume, em função da maior ou menor participação do dejeto suíno.

Para auxiliar no processo de digestão anaeróbia, previamente ao experimento foi preparado o inóculo, caracterizado como lodo anaeróbio ambientado com as amostras e digerido anteriormente ao 
processo. Este continha os microrganismos necessários à digestão anaeróbia sendo capazes de fermentarem o novo material em um menor tempo de detenção, pois de acordo com El Achkar et al. (2016), o inóculo tem efeito na cinética do experimento e não no rendimento final de metano, que depende apenas do teor de matéria orgânica adicionada ao reator.

Considerando que todos os reatores foram preenchidos com $600 \mathrm{~mL}$ de substratos, $30 \%$ deste volume $(180 \mathrm{~mL})$ corresponderam ao inóculo e $70 \%(420 \mathrm{~mL})$ eram referentes à mistura de lodos e sangue e dejeto suíno (DS). Em relação aos $420 \mathrm{~mL}$, a variação do percentual do dejeto suíno e da mistura de substratos se deu conforme ilustrado na Figura 1.

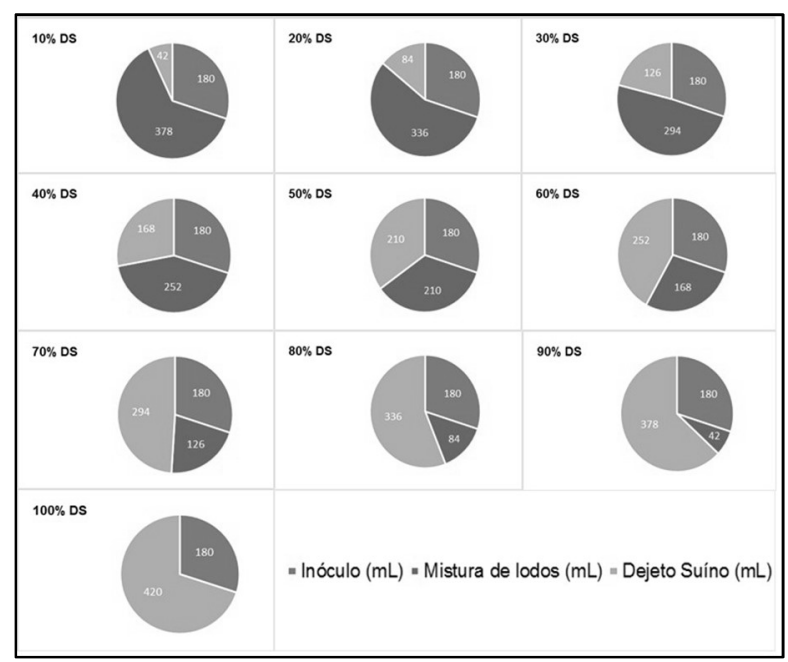

Figura 1: Composição das amostras avaliadas variando-se a participação do dejeto suíno (DS).

\section{Ensaios de digestão anaeróbia}

A pesquisa foi realizada em escala laboratorial e operada em batelada, com amostras em triplicata. Após receberem as amostras, os reatores foram fechados hermeticamente e conectados ao Sistema Automatizado de Medição de Biogás. O experimento foi consolidado quando a produção de biogás decaiu, indicando que uma parcela da matéria orgânica havia sido degradada. Como critério para a finalização dos experimentos, adotou-se o indicado pela norma alemã VDI 4630, encerrando-se os experimentos quando o volume diário de biogás produzido nos reatores foi menor que $1 \%$ do total acumulado por, pelo menos, três dias consecutivos.

Foram utilizados reatores de vidro com capacidade de $1000 \mathrm{~mL}$, preenchidos com $600 \mathrm{~mL}$ de substratos, mantidos em temperatura mesofílica $\left(35^{\circ} \mathrm{C}\right)$ em uma incubadora bacteriológica adaptada, conectada a um sistema automatizado de medição de biogás (KONRAD et al., 2016). Os volumes de biogás gerados nos reatores foram monitorados diariamente através do download dos dados do sistema e exportação dos mesmos para planilhas de controle. O teor de metano presente no biogás foi avaliado através de um sensor específico (Advanced Gasmitter), produzido pela empresa PRONOVA Analysentechnik GmbH $\&$ Co, que detecta o metano na mistura gasosa e apresenta os dados em percentual.

$\mathrm{Na}$ figura 2 estão ilustradas algumas etapas da preparação dos reatores submetidos à experimentação. Nas imagens 2A e 2B, pode-se visualizar os três componentes das triplicatas: inóculo, dejeto suíno e a mistura de lodos e sangue. A imagem $2 \mathrm{C}$ ilustra o preenchimento de todos os reatores com $180 \mathrm{~mL}$ 
de inóculo e a imagem 2D ilustra o preenchimento inicial dos reatores com a mistura, sendo possível identificar a variação nos volumes utilizados que ao final, foram igualados a $600 \mathrm{~mL}$ com a inserção do dejeto suíno nas proporções especificadas.

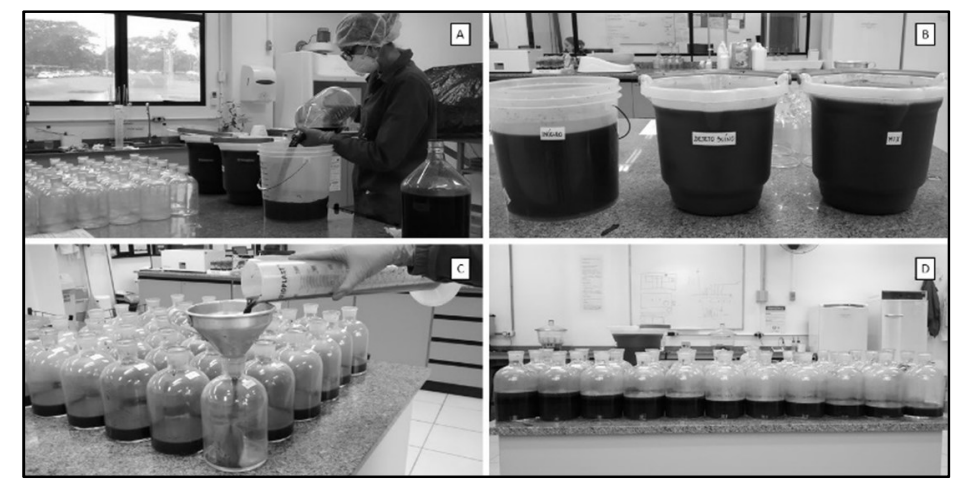

Figura 2: Etapas da preparação do experimento, nas quais A representa o preparo dos componentes da mistura; B ilustra o Inóculo, Dejeto Suíno e Mix; C apresenta o preenchimento dos reatores com inóculo; e D espelha os reatores preenchidos com as parcelas de inóculo e mix determinadas.

\section{RESULTADOS E DISCUSSÃO}

Os resultados obtidos a partir dos ensaios de biogás estão apresentados na tabela 2. Ressalta-se que os valores se referem à média obtida pelas triplicatas, acompanhados do desvio padrão de cada uma delas. Pode-se verificar que o tempo de detenção hidráulico (TDH) das amostras variou de 27 a 59 dias de experimentação, fato esse relacionado ao tempo exigido pelas diferentes misturas para a sua degradação, e, quanto maior o percentual de dejeto suíno (DS) presente na mistura, menor foi o TDH.

Tabela 2: Resultados obtidos nos ensaios de biogás pelas amostras avaliadas.

\begin{tabular}{|c|c|c|c|c|}
\hline Amostra & Biogás $(\mathrm{mL})$ & Metano $(\mathrm{mL})$ & $\mathrm{CH}_{4}(\%)$ & TDH \\
\hline $10 \%$ DS & $18.765 \pm 685$ & $13.123 \pm 570$ & 69,93 & 59 \\
\hline $20 \%$ DS & $16.788 \pm 983$ & $11.894 \pm 744$ & 70,85 & 59 \\
\hline $30 \%$ DS & $15.772 \pm 48$ & $10.829 \pm 46$ & 68,66 & 50 \\
\hline $40 \%$ DS & $12.523 \pm 1.416$ & $8.391 \pm 923$ & 67,01 & 41 \\
\hline $50 \%$ DS & $12.375 \pm 2.209$ & $8.183 \pm 1.522$ & 66,12 & 41 \\
\hline $60 \%$ DS & $11.349 \pm 867$ & $7.459 \pm 688$ & 65,73 & 27 \\
\hline $70 \%$ DS & $9.014 \pm 563$ & $5.884 \pm 397$ & 65,27 & 27 \\
\hline $80 \%$ DS & $6.728 \pm 356$ & $4.274 \pm 258$ & 63,52 & 27 \\
\hline $90 \%$ DS & $5.445 \pm 218$ & $3.343 \pm 104$ & 61,40 & 27 \\
\hline $100 \%$ DS & $3.374 \pm 442$ & $1.953 \pm 308$ & 57,88 & 27 \\
\hline
\end{tabular}



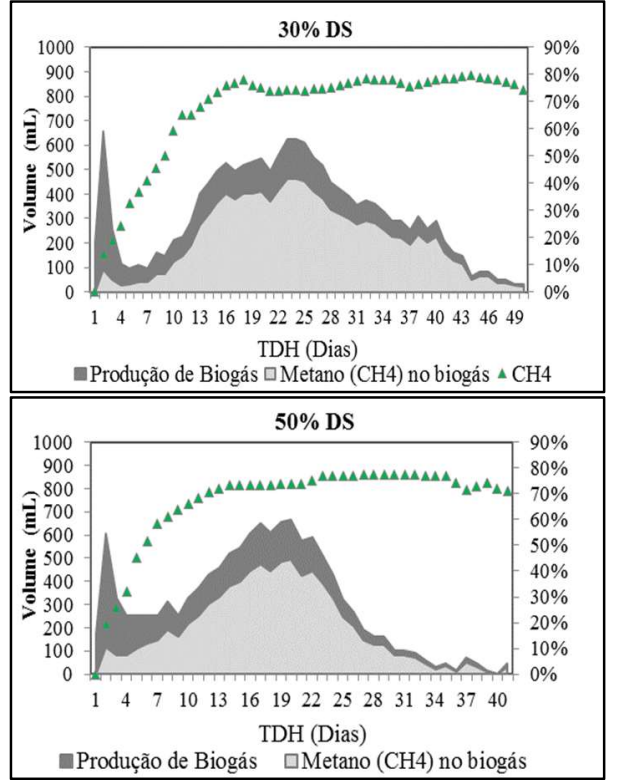

Produção de Biogás $\quad \square$ Metano (CH4) no biogás

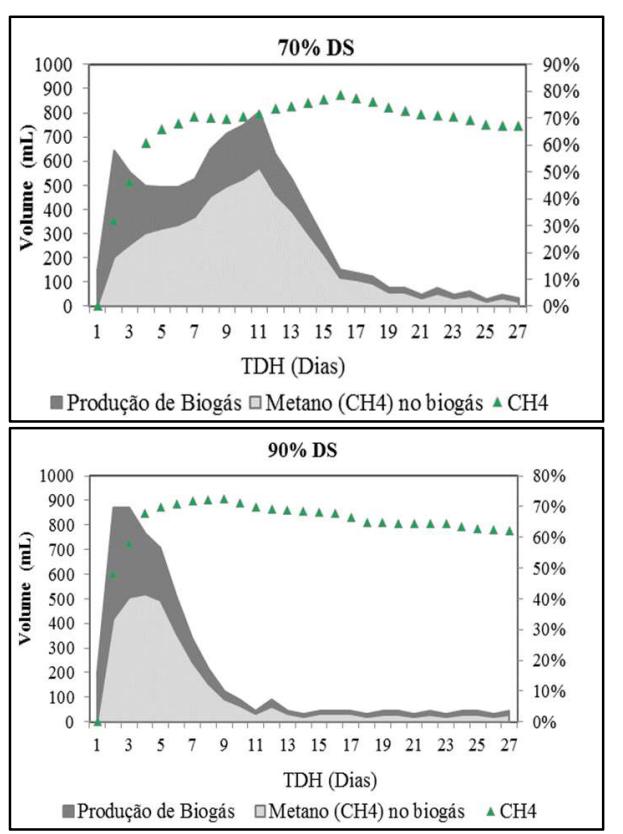

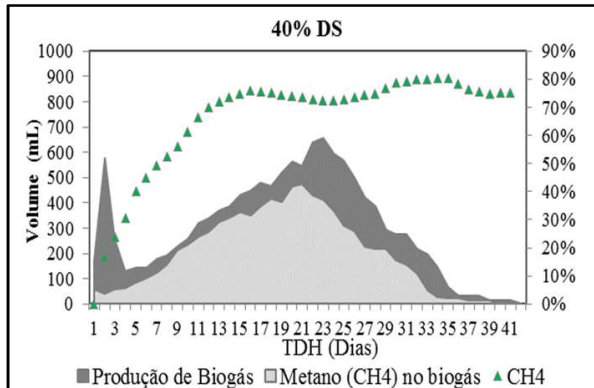

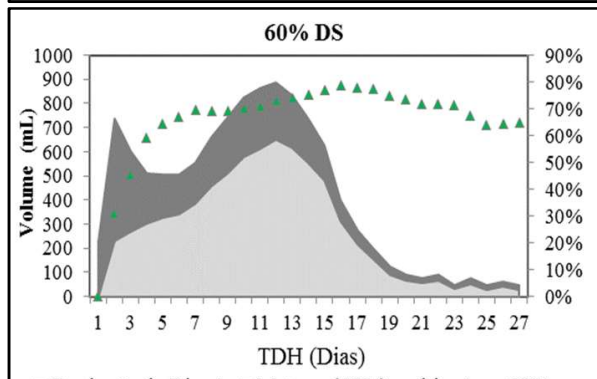

—Produção de Biogás $\square$ Metano (CH4) no biogás $\triangle \mathrm{CH} 4$
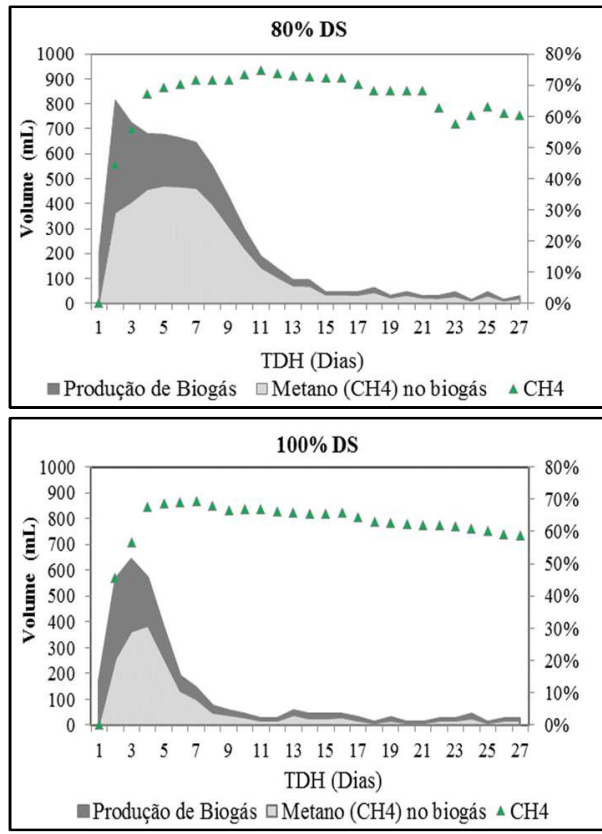

Figura 3: Desempenho diário das amostras em relação à produção de biogás e metano

A Figura 3 reúne os gráficos que ilustram o desempenho diário das amostras, em relação às suas produções volumétricas de biogás e metano e a oscilação nos percentuais de metano durante todo o processo de tratamento. As curvas ilustradas em cada gráfico representam o desenvolvimento diário do processo de biodigestão anaeróbia ao longo do tempo em cada amostra.

Em relação às gerações de biogás e metano, as amostras com os maiores percentuais de participação do dejeto suíno exigiram menores TDH para sua degradação, mas foram também as que obtiveram os menores volumes totais. Segundo Gomes et al. (2011), o TDH em processos de digestão anaeróbia tem relação direta com o teor de sólidos do substrato empregado, neste sentido, ressalta-se que o dejeto suíno utilizado nos experimentos apresentou um teor de sólidos totais de 3,72\%.

Deste modo pode-se presumir que o seu incremento gradual nas amostras provocou também uma diluição gradual e a consequente redução no teor de sólidos, fato que explica a melhoria na cinética da reação (menores tempos de detenção) e os menores volume totais de biogás e metano nas amostras com maior participação de dejeto suíno. 
Acredita-se que, além da diluição proporcionada às amostras, a adição do dejeto suíno foi responsável por facilitar a etapa de hidrólise, pois nos gráficos de geração diária é possível verificar que os maiores volumes de biogás e metano, nas amostras com teores de dejeto suíno superior a $50 \%$ foram produzidos nos primeiros dias de experimentação, enquanto que nas triplicatas com teores de dejeto suíno abaixo de $50 \%$, os maiores volumes foram gerados após 10 ou 15 dias de experimentação, indicando maiores dificuldades na etapa de hidrólise e presumindo-se que estas possam estar relacionadas à presença de compostos complexos, como a gordura originária dos lodos, presentes em maior volume nas misturas com menos dejeto suíno. A Figura 4 apresenta o comparativo dos resultados obtidos nos ensaios de biogás pelas amostras avaliadas.

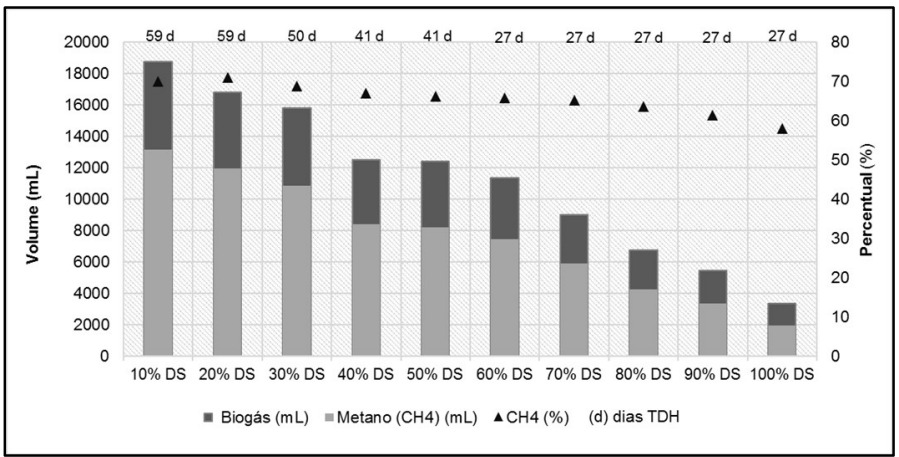

Figura 4: Comparativo da geração acumulada de biogás e metano nas triplicatas.

A tendência apresentada nas produções de biogás e metano indica que, quanto maior o percentual de dejeto suíno na mistura, menor o volume produzido. Mesmo assim, o teor de metano no biogás foi superior a 55\% em todas as amostras, o que é energeticamente interessante, visto que o valor calorífico do biogás é diretamente proporcional à porcentagem de metano na mistura (GALBIATTI et al., 2010) e, portanto, para fins de aproveitamento energético, quanto maior o teor de metano presente no biogás, melhor é a qualidade do mesmo. Presume-se que uma parcela significativa do restante do biogás seja composta por dióxido de carbono $\left(\mathrm{CO}_{2}\right)$, conforme descreve Konrad et al. (2016) em seu estudo sobre a quantificação e a caracterização da produção de biogás em uma planta de escala real.

Por meio da codigestão de substratos algumas vantagens são estabelecidas e o processo de digestão anaeróbia é otimizado, favorecendo a geração de maiores volumes de biogás e metano. A codigestão pode promover estabilidade ao processo de digestão, visto que, quando utilizado um único substrato, as chances de desequilíbrio de nutrientes são maiores (IACOVIDOU et al., 2012; ZHANG et al., 2014). Assim, o uso do dejeto suíno como cosubstrato para a digestão de lodos e sangue emergiu para aumentar a digestibilidade do processo, promover melhoria na produção de biogás e metano e acelerar a taxa de produção (KOCH et al., 2016).

Mata-Alvarez et al. (2014) descreve positivamente a codigestão dos dejetos animais e resíduos agroindustriais. Na combinação de dejetos suínos com resíduos lipídicos, por exemplo, os autores vislumbraram melhorias devido às limitações de cada substrato ter sido complementada. Os dejetos, normalmente possuem baixa carga orgânica e elevados teores de $\mathrm{N}$ amoniacal, enquanto que para os 
resíduos lipídicos, os baixos teores de nitrogênio e a elevada taxa orgânica pode ser entrave pois, dependendo de sua biodegradabilidade, será capaz de gerar grandes quantidades de ácidos graxos em um curto período de degradação. A Tabela 3 ilustra a eficiência média diária da geração de biogás e metano, obtida a partir da razão entre volumes médios de produção pelos dias de TDH de cada amostra, com o objetivo de identificar qual das amostras obteve o melhor desempenho.

Tabela 3: Eficiência média diária da geração de biogás e metano pelas amostras

\begin{tabular}{|c|c|c|}
\hline Amostra & Biogás (mL/dia) & Metano (mL/dia) \\
\hline $\mathbf{1 0 \%}$ DS & 318,05 & 222,42 \\
\hline $\mathbf{2 0 \%}$ DS & 284,54 & 202,22 \\
\hline $\mathbf{3 0 \%}$ DS & 315,44 & 217,05 \\
\hline $\mathbf{4 0 \%}$ DS & 305,43 & 204,66 \\
\hline $\mathbf{5 0 \%}$ DS & 301,84 & 199,59 \\
\hline $\mathbf{6 0 \%}$ DS & 420,34 & 276,27 \\
\hline $\mathbf{7 0 \%}$ DS & 333,84 & 217,91 \\
\hline $\mathbf{8 0 \%}$ DS & 249,20 & 158,29 \\
\hline $\mathbf{9 0 \%}$ DS & 201,66 & 123,82 \\
\hline $\mathbf{1 0 0 \%}$ DS & 124,96 & 72,33 \\
\hline
\end{tabular}

Estes resultados elucidam que a melhor eficiência diária de geração de biogás e metano foi obtida pela mistura contendo $60 \%$ de dejeto suíno. Não houve um comportamento linear entre as amostras que pudesse indicar alguma tendência, visto que a amostra de 60\% DS se destacou entre as demais. 0 argumento sobre a diluição provocada pelo DS, com vistas à facilidade na etapa de hidrólise, pode ser retomado como justificativa para esta amostra ter sido melhor que àquelas com percentuais abaixo de 60\% DS.

Ao mesmo tempo em que essa quantidade de DS possa ter permitido uma parcela de sólidos totais e voláteis maior nesta amostra em relação às amostras com percentuais acima de 60\% DS. Estes dois argumentos combinados buscam tentar explicar esta melhor performance, no entanto, a particularidade das amostras avaliadas deve ser considerada em estudos comparativos e posteriores a este.

\section{CONCLUSÃO}

O efeito sinérgico entre as biomassas combinadas resultou em melhores índices de produção de biogás, se comparado o desempenho das amostras que receberam a mistura de lodos e sangue à amostra tratada individualmente ( $100 \%$ dejeto suíno). Sabe-se que o dejeto suíno é uma biomassa tipicamente empregada em processos de digestão anaeróbia, com recuperação energética do biogás inclusive, os resultados verificados, portanto, indicam que a inserção de outras biomassas ao processo pode resultar em incrementos significativos na produção de biogás sendo o seu aproveitamento energético favorecido.

As amostras com maior participação da mistura de lodos e sangue tiveram os melhores desempenhos, em termos de volumes finais produzidos de biogás e metano, porém isso resultou em maiores tempos de detenção hidráulica. Em termos de eficiência diária de produção de biogás, o melhor resultado foi obtido pela amostra composta por $60 \%$ de dejeto suíno e $40 \%$ da mistura de lodos e sangue. De modo geral, constatou-se que, em todas as amostras os volumes mais significativos foram produzidos nos primeiros 27 dias do experimento. 
A codigestão de biomassas residuais é capaz de promover melhores rendimentos na produção de biogás para fins de seu aproveitamento como fonte renovável de energia, ao tempo em que surge como uma etapa para o tratamento de lodos e subprodutos agroindustriais, com possibilidade de redução de suas cargas orgânicas.

\section{REFERÊNCIAS}

CANDIANI, G.; TORRES, D. C.. Análise qualitativa e quantitativa da produção de biogás em aterro sanitário. Revista Ibero-Americana de Ciências Ambientais, Aquidabã, v.6, n.1, p.285-292, 2015. DOI: http://doi.org/10.6008/SPC2179-6858.2015.001.0022

CLARK, J. H.; LUQUE, R.; MATHARU, A. S.. Green Chemistry, Biofuels, and Biorefinery. Annual Review of Chemical and Biomolecular Engineering, v.3, p.183-207, 2012. DOI: http://doi.org/10.1146/annurev-chembioeng-062011$\underline{081014}$

COSTA, R. J.. Produção e Aplicação de Biogás. Dissertação (Mestrado em Automação e Comunicações em Sistemas de Energia) - Instituto Superior de Engenharia de Coimbra, Coimbra, 2011.

DAL SOLER, A. L.. Levantamento de dados da geração e caracterização de dejetos na suinocultura em fase de creche e terminação. Monografia (Graduação em Engenharia Ambiental) - Centro Universitário Univates, Lajeado, 2012.

EL ACHKAR, J. H.; LENDORMI, T.; HOBAIKA, Z.; SALAMEH, D.; LOUKA, N.; MAROUN, R. G.; LANOISELLÉ, J. L.. Anaerobic digestion of grape pomace: Biochemical characterization of the fractions and methane production in batch and continuous digesters. Revista Waste Management, v.50, p.275-282, 2016. DOI:

http://doi.org/10.1016/j.wasman.2016.02.028

FERRAREZ, A. H.; FILHO, D. O.; TEIXEIRA, C. A.. Independência energética de granja suinícola a partir do uso de biogás. Revista Engenharia na Agricultura, v.18, n.3, p.248-257, 2010.

GALBIATTI, J. A.; CARAMELO, A. D.; SILVA, F. G.; GERARDI, E. A. B.; CHICONATO, D. A.. Estudo qualiquantitativo do biogás produzido por substratos em biodigestores tipo batelada. Revista Brasileira de Engenharia Agrícola e Ambiental, v.14, n.4, p.432-437, 2010. DOI: http://doi.org/10.1590/S1415$\underline{43662010000400013}$

GOMES, F. O. C.; CAPPI, N.. Redução de sólidos de dejetos de poedeiras em biodigestores operados com diferentes tempos de retenção hidráulica. Periódicos UEM, Maringá, v.1, n.1, 2011

HIDALGO, D.; MARTÍN-MARROQUÍN, J. M.. Effects of inoculum source and co-digestion strategies on anaerobic digestion of residues generated in the treatment of waste vegetable oils. Journal of Environmental Management, v.142, p.17-22, 2014. DOI: http://doi.org/10.1016/j.jenvman.2014.04.004
IACOVIDOU, E.; OHANDJA, D. G.; VOULVOULIS, N.. Food waste co-digestion with sewage sludge: Realising its potential in the UK. Journal of Environmental Management, v.112, p.267-274, 2012. DOI:

http://doi.org/10.1016/j.jenvman.2012.07.029

KOCH, K.; PLABST, M.; SCHMIDT, A.; HELMREICH, B.; DREWES, J. E.. Co-digestion of food waste in a municipal wastewater treatment plant: comparison of batch tests and full-scale experiences. Revista Waste Management, v.47, p.28-33, 2016. DOI: http://doi.org/10.1016/j.wasman.2015.04.022

KONRAD, O.; AKWA, J. V.; KOCH, F. F.; LUMI, M.; TONETTO, J. F.. Quantification and characterization of the production of biogas from blends of agro-industrial wastes in a large-scale demonstration plant. Acta Scientiarum Technology, v.38, p.415-421, 2016. DOI: http://doi.org/10.4025/actascitechnol.v38i4.28649

KONRAD, O.; BEZAMA, A. B.; PRADE, T.; BACKES, G. M.; OESCHNER, H.. Enhancing the analytical capacity for biogas development in Brazil: assessment of an original measurement system for low biogas flow rates out of agricultural biomass residues. Journal of the Brazilian Association of Agricultural Engineering, v.36, p.792-798, 2016. DOI: http://doi.org/10.1590/1809-4430Eng.Agric.v36n5p792-798/2016

KONRAD, O.; LUMI, M.; HEBERLE, A. N. A.; TONETTO, J. F.; CASARIL, C. E.. A influência da codigestão de óleo vegetal residual na geração de biogás por lodo de estação de tratamento de efluentes. Revista Brasileira de Energias Renováveis, v.2, p.1-20, 2013. DOI: http://doi.org/10.5380/rber.v2i4.34840

MATA-ALVAREZ, J.; DOSTA, J.; ROMERO-GÜIZA, M. S.; FONOLL, X.; PECES, M.; ASTALS, S.. A critical review on anaerobic co-digestion achievements between 2010 and 2013. Renewable and Sustainable Energy Reviews, Amsterdam, v.36, p.412-27, 2014. DOI: http://doi.org/10.1016/j.rser.2014.04.039

MIYAWAKI, B.. Purificação de biogás através de cultivo de microalgas em resíduos agroindustriais. Dissertação (Mestrado) - Universidade Federal do Paraná, Curitiba, 2014.

PRATI, L.. Geração de energia elétrica a partir do biogás gerado por biodigestores. Monografia (Graduação em Engenharia Elétrica) - Universidade Federal do Paraná, Curitiba, 2010.

RÜHL C.; APPLEBY, P.; FENNEMA, J.; NAUMOV, A.; SCHAFFER, M.. Economic development and the demand for energy: A historical perspective on the next 20 years. Revista 
Energy Policy, v.50, p.109-116, 2012. DOI:

http://doi.org/10.1016/j.enpol.2012.07.039

SALOMON, K. R.; LORA, E. E. S.. Estimativa do potencial de geração de energia para diferentes fontes de biogás no Brasil. Biomassa \& Energia, v.2, n.1, p.57-67, 2005.
ZHANG, C.; SU, H.; BAEYENS, J.; TAN, T.. Reviewing the anaerobic digestion of food waste for biogas production. Renewable and Sustainable Energy Reviews, v.38, p.383392, 2014. DOI: http://doi.org/10.1016/j.rser.2014.05.038 